\title{
Solute Trapping in Silicon by Lateral Motion of $\{111\}$ Ledges
}

\section{Citation}

Aziz, Michael J. and C. W. White. 1986. Solute trapping in silicon by lateral motion of $\{111\}$ ledges. Physical Review Letters 57, no. 21: 2675-2678.

\section{Published Version}

http://dx.doi.org/10.1103/PhysRevLett.57.2675

\section{Permanent link}

http://nrs.harvard.edu/urn-3:HUL.InstRepos:2913046

\section{Terms of Use}

This article was downloaded from Harvard University's DASH repository, and is made available under the terms and conditions applicable to Other Posted Material, as set forth at http:// nrs.harvard.edu/urn-3:HUL.InstRepos:dash.current.terms-of-use\#LAA

\section{Share Your Story}

The Harvard community has made this article openly available.

Please share how this access benefits you. Submit a story.

Accessibility 


\title{
Solute Trapping in Silicon by Lateral Motion of $\{111\}$ Ledges
}

\author{
M. J. Aziz ${ }^{(a)}$ and C. W. White \\ Solid State Division, Oak Ridge National Laboratory, Oak Ridge, Tennessee 37831
}

(Received 18 June 1986)

\begin{abstract}
The orientation dependence of the nonequilibrium partition coefficient of $\mathrm{Bi}$ in $\mathrm{Si}$ at constant solidliquid interface velocity has been measured. The partition coefficient, measured with pulsed-laser melting techniques on a series of $\mathrm{Si}$ wafers cut at $5^{\circ}$ increments from (110) through (111) to (001), is sharply peaked at (111) and decreases monotonically with increasing inclination from (111). The results suggest that crystal growth and solute trapping occur by the lateral motion of $\{111\}$ ledges.
\end{abstract}

PACS numbers: $61.50 . \mathrm{Cj}, 68.45 .-\mathrm{v}, 81.30 . \mathrm{Fb}, 82.20 . \mathrm{Pm}$

One of the most interesting topics in the study of nonequilibrium processes is the response of an interface to the local thermodynamic conditions imposed upon it. Besides providing the necessary boundary conditions on equations describing mass and heat transport in the bulk of the two phases separated by a moving interface, measurements of the interface response functions are our key to understanding the fundamental atomic processes that lead to phase transformations. In the case of solidification of a two-component system at ambient pressure, the response functions provide two independent relations between four variables ${ }^{1}$ : the solute concentration on both sides of the interface, the interface temperature, and the interface velocity. Given, for example, an interface temperature and a composition of the liquid at the interface, the response functions yield the interface velocity and the composition of the growing solid.

The common assumption of local equilibrium at the interface, which provided the simplest possible form for the response functions, was laid to rest by Baker and Cahn, ${ }^{2}$ who demonstrated that the chemical potential of $\mathrm{Cd}$ increases as a result of rapid solidification during splat quenching of $\mathrm{Zn}(\mathrm{Cd})$ alloys. This phenomenon, termed "solute trapping," was shown by Baeri and coworkers ${ }^{3}$ and by White and co-workers ${ }^{4}$ to result also from rapid solidification of a thin surface melt following pulsed-laser irradiation of doped semiconductors. They were able to estimate the ratio of the solute concentration in the growing solid to that in the liquid at the interface, known as the nonequilibrium partition coefficient $k$, and its dependence on interface velocity $v$. Baeri and co-workers also observed in such experiments on $\mathrm{Bi}$ implanted $\mathrm{Si}$ that at equal velocities $k$ for the (001) orientation was significantly less than $k$ for (111), but this difference seemed to disappear as $v$ approached $\sim 5$ $\mathrm{m} / \mathrm{s}$. They also observed intermediate amounts of trapping $^{5}$ of $\mathrm{In}$ in $\mathrm{Si}(110)$ and (112). These observations have been accounted for $^{6}$ with a reduced impurity mobility as a result of substantially more undercooling on (111) than on (100) at equal growth velocities. However, successful fitting requires much more interfacial undercooling than has been measured. ${ }^{7,8}$ It has also been suggested $^{9}$ that the greater degree of trapping at (111) might be due to the lateral speed of (111) ledges for a (111) interface being greater than the lateral speed of (111) ledges for a (100) interface moving at the same $v$.

Solute trapping is described theoretically ${ }^{10}$ in terms of a superposition of two reactions at the interface, the attachment of atoms independent of species at lattice sites, and solute-solvent redistribution across the interface by an interdiffusive process. A transition from equilibrium partitioning $\left(k=k_{e}\right.$, the ratio between the solidus and liquidus compositions on the equilibrium phase diagram) to complete solute trapping $(k \rightarrow 1)$ occurs as the interface speed surpasses the maximum speed with which the impurity can diffuse at the interface to remain out of the growing solid. The predicted velocity dependence of $k$ depends on the mode of interface motion. If growth occurs by the periodic lateral passage of steps alternating with diffusive escape of the trapped solute, the transition from $k=k_{e}$ to $k=1$ is sharper than if growth is continuous and steady state on a local microscopic scale, as might be expected for a diffuse interface. Aziz et al. ${ }^{11}$ made accurate measurements of the velocity dependence of $k$ of $\mathrm{Bi}$ in $\mathrm{Si}(001)$ and showed that the results were well described by the model for continuous growth:

$$
k=\left[\left(v / v_{D}\right)+k_{e}\right] /\left[\left(v / v_{D}\right)+1\right],
$$

with a value of $32 \mathrm{~m} / \mathrm{s}$ for the only free parameter $v_{D}$, the maximum speed of interdiffusion. In contrast to the expected results from the motion of (111) steps, similar results at the (111) orientation ${ }^{12}$ were also best described by the continuous growth model, only with a smaller value of $v_{D}$. We will resolve this puzzle below.

There is strong evidence that in Si the crystal-melt interface with orientation near $\{111\}$ propagates by the lateral passage of $\{111\}$ steps, at both very low ${ }^{13}$ and very high $^{14}$ interface speeds. In addition, molecular-dynamics simulations by Landman et al..$^{15}$ and Abraham and Broughton ${ }^{16}$ show the equilibrium (111) interface to be sharp and the (100) interface diffuse. However, a breakup of the (100) interface into $\{111\}$ facets was apparently observed by the former but not by the latter investigators.

The present study of the orientation dependence of $k$ was undertaken to provide insight into the mechanism of 
crystal growth and solute incorporation in $\mathrm{Si}$. Wafers were cut from a single crystal of p-type (B-doped), 30$\Omega-\mathrm{cm}$, float-zoned $\mathrm{Si}$ at orientations varying in $5^{\circ}$ increments from (110) through (111) to (001) and given identical implants of ${ }^{209} \mathrm{Bi}^{++}\left(250 \mathrm{keV}, 10^{15} / \mathrm{cm}^{2}, 3\right.$ $\left.\mu \mathrm{A} / \mathrm{cm}^{2}, 77 \mathrm{~K}\right)$, creating an amorphous surface layer 180 $\mathrm{nm}$ thick. They were then irradiated by use of a pulsed excimer laser under conditions $\left(1.1 \mathrm{~J} / \mathrm{cm}^{2}\right.$, wavelength $248 \mathrm{~nm}$, duration $25 \mathrm{~ns}$ FWHM) calculated to effect melting through the entire amorphous layer and into the single-crystal substrate, and epitaxial crystallization at interface velocities of 5 or $1.7 \mathrm{~m} / \mathrm{s}$. These velocities were obtained by holding the substrate at room temperature (for $5 \mathrm{~m} / \mathrm{s}$ ) or $550^{\circ} \mathrm{C}$ (for $1.7 \mathrm{~m} / \mathrm{s}$ ) during laser irradiation. The laser pulse energy was calibrated with a calorimeter and subsequently monitored by use of timeresolved reflectivity to measure the melt duration for each shot. The elevated sample temperature was checked by measurement of the solid-phase epitaxial growth rate of pure-crystal $\mathrm{Si}$ into amorphous $\mathrm{Si}$ and also by comparison of the melt durations resulting from

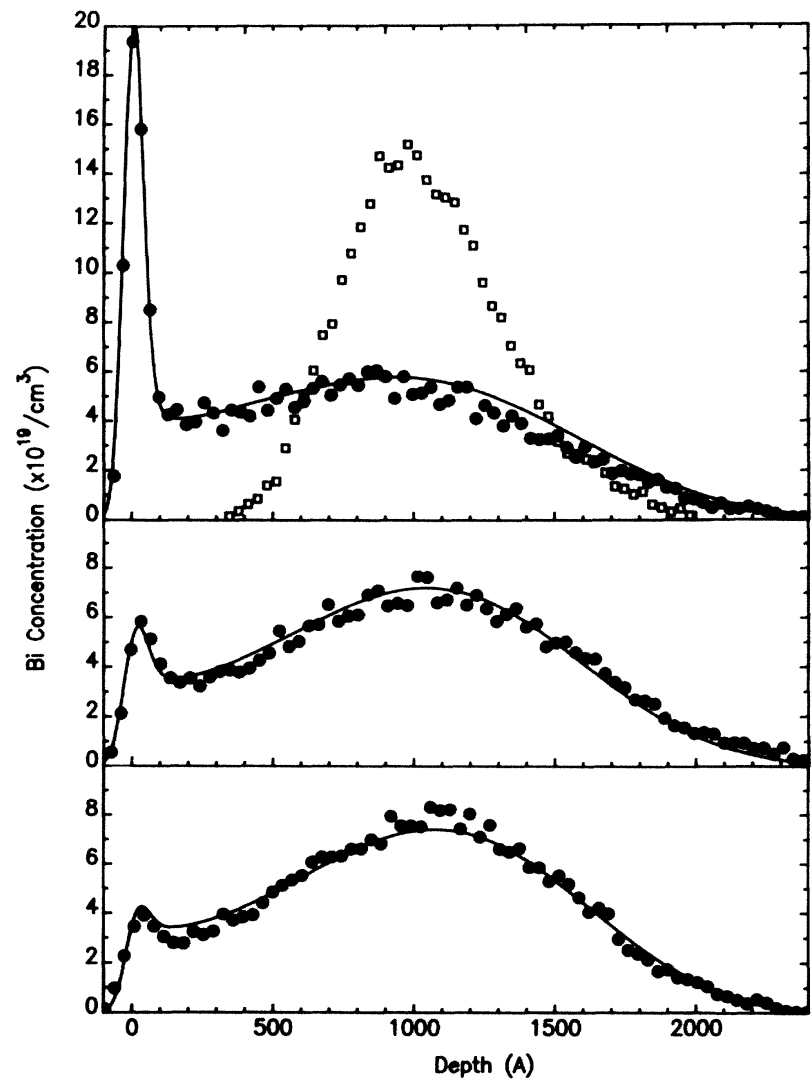

FIG. 1. RBS depth profile of $\mathrm{Bi}$ in $\mathrm{Si}$ before (squares) and after (circles) regrowth from pulsed laser melting. Melt duration $90 \mathrm{~ns}$, melt depth $250 \mathrm{~nm}$, average regrowth speed $5 \mathrm{~m} / \mathrm{s}$. Top: (001), $v_{D}=28 \mathrm{~m} / \mathrm{s}, k$ at $5 \mathrm{~m} / \mathrm{s}=0.15$; middle: $5^{\circ}$ off (111) toward $(001), v_{D}=10 \mathrm{~m} / \mathrm{s}, k$ at $5 \mathrm{~m} / \mathrm{s}=0.33$; bottom: (111), $v_{D}=6.6 \mathrm{~m} / \mathrm{s}, k$ at $5 \mathrm{~m} / \mathrm{s}=0.43$. pulsed-laser irradiation of single crystals at room temperature and elevated temperature with heat-flow calculations. The relevant optical and thermophysical parameters of liquid, crystalline, and amorphous $\mathrm{Si}$ are known at present with sufficient accuracy that the most recent heat-flow calculations yield good agreement with experiment. ${ }^{17}$ The interface mobility during rapid solidication of these samples should in no case be less than $\frac{1}{18}$ $\mathrm{m} / \mathrm{s} \cdot \mathrm{K}^{7,8}$ and the variation of interfacial undercooling with orientation seems to be roughly half its maximum value $^{8}$; thus samples of different orientations given identical laser treatments will respond with virtually identical interface velocities that can be calculated in the heatflow limit. Results of heat-flow calculations employing mobilities in this regime or greater for the interface boundary condition were insensitive to the assumed mobility under our experimental conditions.

The as-implanted and final $\mathrm{Bi}$ depth profiles were determined by Rutherford backscattering spectrometry (RBS) carried out in a grazing-exit-angle geometry. The partition coefficient for each sample was determined by comparison of the final $\mathrm{Bi}$ profile to a numerical simulation with use of a finite-element solution of the diffusion equation, with the measured as-implanted profile and the calculated melt depth as functions of time for each sample. Impurity diffusion was assumed to occur in the liquid phase but was neglected in the solid. During solidification, a fraction $k$ [given by Eq. (1) with $k_{e}=7 \times 10^{-4}$ ] of the impurity in the liquid at the interface was incorporated into the crystal. The parameters allowed to vary were the bulk liquid-phase diffusivity $D_{L}$ and the diffusive speed $v_{D}$. Since the interface speed varies only slightly during solidification, simulations with constant $v_{D}$ are very similar to simulations as they have usually been done, with constant $k$. The former are accurate and reduce the error in the fit somewhat. Comparison with the measured profiles yielded unique values for both $D_{L}$ and $v_{D}$. In all cases, a diffusivity of $D_{L}=2 \times 10^{-4} \mathrm{~cm}^{2} / \mathrm{s}$ provided the best fit to the data, as had been found previously. $3,4,11$

In Fig. 1 we show $\mathrm{RBS}$ depth profiles of $\mathrm{Bi}$ in $\mathrm{Si}$ of several orientations following resolidification at $5 \mathrm{~m} / \mathrm{s}$ from pulsed-laser melting. The open squares represent the measured as-implanted profile used as a starting point in the simulations. The curves are "best fit" simulations with $v_{D}=28 \mathrm{~m} / \mathrm{s}$ for $(001), 10 \mathrm{~m} / \mathrm{s}$ for a wafer oriented $5^{\circ}$ off $(111)$ towards $(001)$, and $6.6 \mathrm{~m} / \mathrm{s}$ for (111) in Eq. (1). The corresponding partition coefficients at $5 \mathrm{~m} / \mathrm{s}$ are $0.15,0.33$, and 0.43 , respectively. The $\mathrm{Bi}$ zone refined to the free surface appears as a surface peak of finite width in the RBS spectra because of the 14-keV detector resolution, which has been convoluted with the simulations for comparison with the data. The amount of zone-refined $\mathrm{Bi}$ is much greater at (001) and is even significantly greater $5^{\circ}$ off (111) than at (111), reflecting the great variation of the partition coef- 


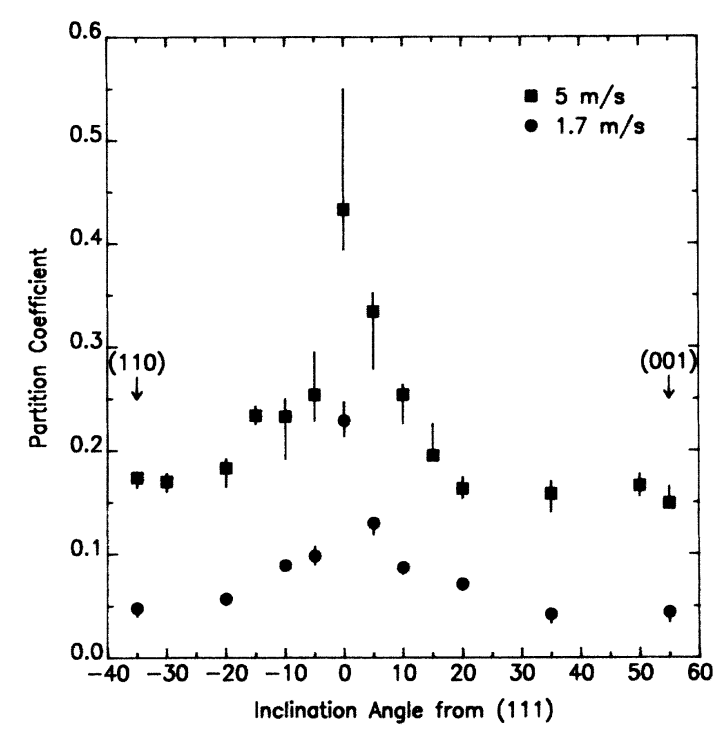

FIG. 2. Orientation dependence of partition coefficient at $1.7 \mathrm{~m} / \mathrm{s}$ (circles) and $5 \mathrm{~m} / \mathrm{s}$ (squares).

ficient with orientation. In Fig. 2 we plot the orientation dependence of $k$ at $5 \mathrm{~m} / \mathrm{s}$ for samples laser treated at room temperature, and $k$ at $1.7 \mathrm{~m} / \mathrm{s}$ for samples treated at $550^{\circ} \mathrm{C}$. Each point near (111) represents a compilation of the results on several identical samples. The error bars represent $30 \%$ confidence limits. At both 1.7 and $5 \mathrm{~m} / \mathrm{s}$ the partition coefficient is sharply peaked at (111). Insight into the results can be gained by consideration of the orientation dependence of the apparent diffusive speed used to fit Eq. (1) to each spectrum, as shown in Fig. 3. For a given orientation, the diffusive speed necessary to provide the best fit is approximately the same at both 1.7 and $5 \mathrm{~m} / \mathrm{s}$. The fact that for different regrowth speeds the values of $v_{D}$ so obtained are nearly equal for any given orientation is evidence that Eq. (1) describes the velocity dependence of $k$ at all orientations. Fitting, for example, to the stepwise growth model at a given orientation requires very different values of $v_{D}$ at these two velocities, which is not a plausible interpretation of the data. The differences at large inclinations from (111) might have some significance. However, the value of $v_{D}=32 \mathrm{~m} / \mathrm{s}$ at $(001)$, bracketed by the current data, was found to describe solute trapping adequately for all measured velocities between 2 and $14 \mathrm{~m} / \mathrm{s}$ in previous work. ${ }^{11}$ The solid line in Fig. 3, which fits the data reasonably well, is given by $v_{D}=(70 \mathrm{~m} / \mathrm{s}) \sin |\theta|$, where $\theta$ is the abscissa.

The results are interpreted as crystal growth occurring by the passage of (111) ledges with lateral speed $v_{L}=v / \sin |\theta|$, as shown in Fig. 4. The absence of cusps at (110) and (001) in Fig. 3 suggests the absence of ledges having these orientations on surfaces near these orientations. With this model, the velocity dependence will continue to follow the continuous rather than the

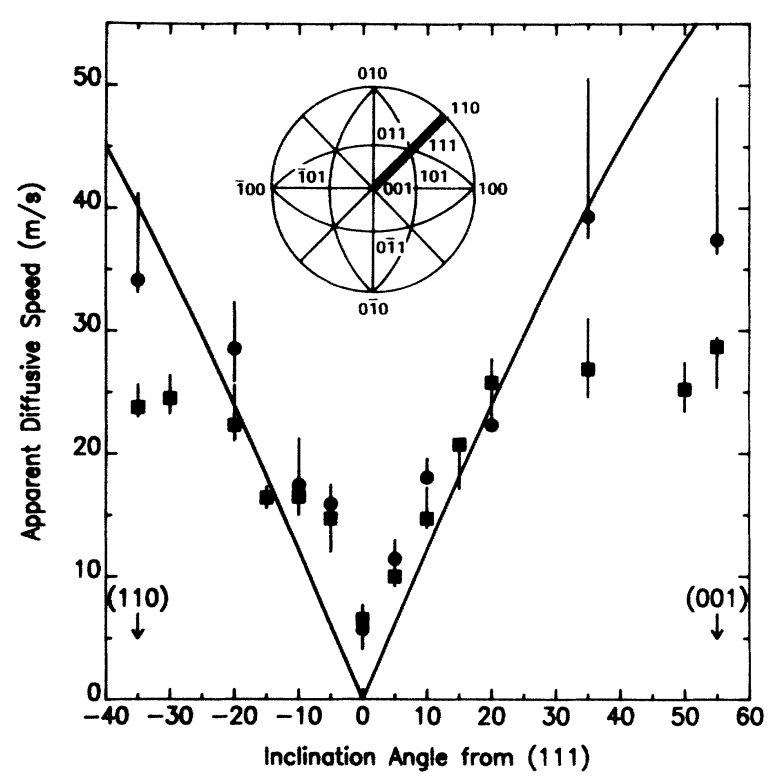

FIG. 3. Orientation dependence of apparent diffusive speed at $1.7 \mathrm{~m} / \mathrm{s}$ (circles) and $5 \mathrm{~m} / \mathrm{s}$ (squares). Curve is $v_{D}=(70$ $\mathrm{m} / \mathrm{s}) \sin |\theta|$.

stepwise growth model if, contrary to our original assumption in the latter, ${ }^{10}$ there is negligible solute escape from the terrace once the ledge passes. Rather, lateral escape could occur at the edge of the moving step itself. This interpretation is plausible since we expect the solute atom on the terrace to be triply or quadruply bonded to the crystal once the ledge passes. In addition, the ledges may be several monolayers in height, thus eliminating the possibility for most of the solute to escape through the terrace. Atoms at the edge of the step, on the other hand, will have fewer bonds to the crystal, which would allow more rapid exchange from the solid into the liquid. Since from entropic considerations we expect the steps to be heavily kinked and therefore diffuse laterally, the kinetics of continuous lateral ledge motion versus lateral solute-solvent redistribution lead to Eq. (1), with $v$ replaced by $v_{L}$ and $v_{D}$ replaced by a maximum speed $v_{D}^{L}$ of redistribution across the step edge:

$$
k(v, \theta)=\left\{\left[v_{L}(\theta) / v_{D}^{L}\right]+k_{e}\right\} /\left\{\left[v_{L}(\theta) / v_{D}^{L}\right]+1\right\} .
$$

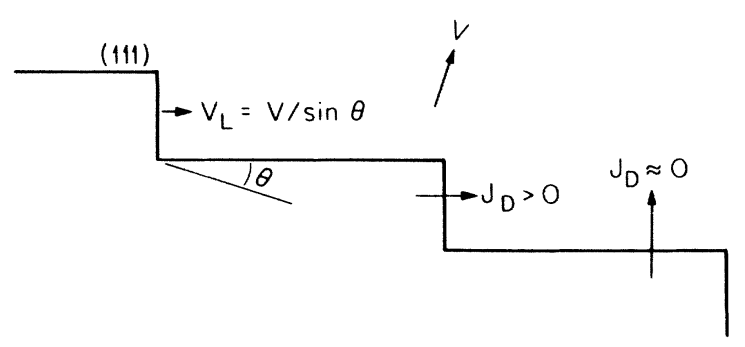

FIG. 4. Solute trapping by lateral passage of (111) step, with lateral solute escape flux at edge of moving step. 
Although conceptually quite simple, such a model accounts remarkably well for partitioning of $\mathrm{Bi}$ in $\mathrm{Si}$ over a wide range of orientations and velocities, with a single fitting parameter of $v_{D}^{L}=70 \mathrm{~m} / \mathrm{s}$. Nevertheless, if one looks precisely along (111) or at large inclinations from (111), the possibility for further refinement of the model is evident. More accurate work, perhaps involving direct velocity measurements, ${ }^{7,11}$ may be necessary before refinement by, e.g., allowing a lesser amount of solute escape through the (111) terraces, is warranted. Finally, note how close the coefficient for interdiffusion across the step, i.e., the product of $v_{D}^{L}$ and the (111) layer spacing of $3.1 \AA$, is to the measured bulk liquid diffusivity of $2 \times 10^{-4} \mathrm{~cm}^{2} / \mathrm{s}$.

We thank T. B. Cook, III, for expert technical assistance, M. O. Thompson for making his heat-flow and diffusion programs available to us, and F. W. Young, Jr., for helpful discussions. This research was sponsored by the Division of Materials Sciences, U.S. Department of Energy, under Contract No. DE-AC05-84OR21400 with Martin Marietta Energy Systems, Inc. One of us (M.J.A.) was supported in part by an appointment to the U.S. Department of Energy Faculty Research Participation program administered by Oak Ridge Associated Universities and in part by the Harvard University $\mathrm{Ma}$ terials Research Laboratory under National Science Foundation Grant No. NSF-DMR-83-16979.

\footnotetext{
(a) Present address: Division of Applied Sciences, Harvard University, Cambridge, MA 02138.

${ }^{1}$ J. C. Baker and J. W. Cahn, in Solidification (American Society for Metals, Cleveland, 1969), pp. 23-58.

2J. C. Baker and J. W. Cahn, Acta Metall. 17, 575 (1969).

${ }^{3}$ P. Baeri, J. M. Poate, S. U. Campisano, G. Foti, E. Rimini, and A. G. Cullis, Appl. Phys. Lett. 37, 912 (1980); P. Baeri, G. Foti, J. M. Poate, S. U. Campisano, and A. G. Cullis, Appl. Phys. Lett. 38, 800 (1981).

${ }^{4}$ C. W. White, S. R. Wilson, B. R. Appleton, and F. W. Young, Jr., J. Appl. Phys. 51, 738 (1980); C. W. White, B. R.
}

Appleton, B. Stritzker, D. M. Zehner, and S. R. Wilson, in Laser and Electron-Beam Solid Interactions and Materials Processing, edited by J. F. Gibbons, L. D. Hess, and T. W. Sigmon, Materials Research Society Symposia Proceedings Vol. 1 (North-Holland, Amsterdam, 1981), p. 59.

${ }^{5} \mathrm{~J}$. M. Poate, in Laser and Electron-Beam Interactions with Solids, edited by B. R. Appleton and G. K. Celler, Materials Research Society Symposia Proceedings Vol. 4 (NorthHolland, Amsterdam, 1982), p. 121.

${ }^{6} \mathrm{~K}$. A. Jackson, in Surface Modification and Alloying by Laser, Ion and Electron Beams, edited by J. M. Poate, G. Foti, and D. C. Jacobson (Plenum, New York, 1983), p. 62; G. H. Gilmer, in Laser-Solid Interactions and Transient Thermal Processing of Materials, edited by J. Narayan, W. L. Brown, and R. A. Lemons, Materials Research Society Symposia Proceedings Vol. 13 (North-Holland, Amsterdam, 1983), p. 249.

${ }^{7}$ G. J. Galvin, J. W. Mayer, and P. S. Peercy, Appl. Phys. Lett. 46, 644 (1985); M. O. Thompson, P. H. Bucksbaum, and J. Boker, in Energy Beam-Solid Interactions and Transient Thermal Processing, edited by D. K. Biegelsen, G. A. Rozgonyi, and C. V. Shank (Materials Research Society, Pittsburgh, 1985), p. 181; J. Y. Tsao, M. J. Aziz, M. O. Thompson, and P. S. Peercy, Phys. Rev. Lett. 56, 2712 (1986).

${ }^{8}$ B. C. Larson, J. Z. Tischler, and D. M. Mills, J. Mater. Res. 1, 144 (1986).

${ }^{9}$ F. Sapepen and D. Turnbull, in Laser Annealing of Semiconductors, edited by J. M. Poate and J. W. Mayer (Academic, New York, 1982), p. 33.

${ }^{10}$ M. J. Aziz, J. Appl. Phys. 53, 1158 (1979), and Appl. Phys. Lett. 43, 552 (1983).

${ }^{11}$ M. J. Aziz, J. Y. Tsao, M. O. Thompson, P. S. Peercy, and C. W. White, Phys. Rev. Lett. 56, 2489 (1986).

${ }^{12}$ M. J. Aziz and C. W. White, unpublished.

${ }^{13}$ T. F. Ciszek, J. Cryst. Growth 10, 263 (1971).

${ }^{14}$ D. M. Zehner, C. W. White, and G. W. Ownby, Surf. Sci. 92, L67 (1980).

${ }^{15}$ U. Landman, W. D. Luedtke, R. N. Barnett, C. L. Cleveland, M. W. Ribarsky, E. Arnold, S. Ramesh, H. Baumgart, A. Martinez, and B. Khan, Phys. Rev. Lett. 56, 155 (1986).

${ }^{16}$ F. F. Abraham and J. Q. Broughton, Phys. Rev. Lett. 56, 734 (1986).

${ }^{17}$ M. J. Aziz, C. W. White, J. Narayan, and B. Stritzker, J. Phys. (Paris), Colloq. (to be published). 